\title{
Unveiling the experiences of women of reproductive age with access to iron-rich food and the use of gutka: an exploratory study from a coastal slum of Karachi, Pakistan
}

Ameer Muhammad

VITAL Pakistan Trust

Eleze Tariq

Aga Khan University Medical College Pakistan

Daniyaal Ahmad Cheema

Aga Khan University Medical College Pakistan

Uzma Khan

VITAL Pakistan Trust

Sarah Saleem

Aga Khan University

Yasir Shafiq ( $\nabla$ yasir.shafiq@vitalpakistantrust.org )

VITAL Pakistan Trust https://orcid.org/0000-0003-1576-724X

Research article

Keywords: Iron-rich food items, gutka use, nonpregnant MWRA

Posted Date: October 13th, 2020

DOI: https://doi.org/10.21203/rs.3.rs-89503/v1

License: (c) (i) This work is licensed under a Creative Commons Attribution 4.0 International License.

Read Full License 


\section{Abstract}

\section{Background}

Anemia among married women of reproductive age (MWRA) is an emerging public health issue. With the growing prevalence in coastal slums, understanding of community perceptions, practices and attitudes towards consuming iron-rich food items is very crucial. An in-depth understanding of why community women are consuming gutka is also important in these slums. The aim of this paper is to present the findings of this qualitative study to better understand community perceptions and experiences regarding access to iron-rich food and use of gutka.

\section{Method}

A simple exploratory design using focus group discussions with nonpregnant MWRA and community health workers as well as thorough interviews with different shopkeepers were performed at Rehri Goth, a coastal slum at Karachi, Pakistan. Further, observational visits were also conducted to perform a market survey and to explore the situation regarding the availability of iron-rich food items in the community.

\section{Results}

Community-level knowledge and understanding on consuming iron-rich food items was poor, and many participants shared concerns regarding accessibility in terms of purchasing power as well as poor availability of these food items in the community as the key issues. These issues are rooted in the sociocultural beliefs that lead to adopting behaviors that result in the use of monotonous diet. These findings were consistent with the fact that observational visits revealed that the community has very low availability of four iron-rich items. Meat shops are only available in $21.4 \%$ of the area, and beef availability was only $41.7 \%$ during observational visits. Additionally, gutka consumption is considered by locals as a solution to poor accessibility of food.

\section{Conclusion}

Study findings suggest that strategies should be developed at the policy-forming and implementation level to increase awareness about consuming iron-rich food items as well as initiatives to improve the accessibility to these items.

\section{Background}

Anemia among women of reproductive age is one of the emergent global health problems. Approximately 468.9 million of nonpregnant women are anemic worldwide, (1) and the number is 32.4 million in pregnant women. (2) Each year, $20 \%$ of maternal mortality (3) and $18-21 \%$ of perinatal mortality is attributable to maternal anemia. (4) Pakistan is among the countries where anemia among these women is prevalent given that approximately $50 \%$ of women samples in a national nutrition survey are anemic. (5) The causes of anemia are varied, but iron deficiency is the one of the leading causes of anemia. $(6,7)$ 
Especially in the context of low-and middle-income countries, the issue is rooted in poverty, food insecurity, malnutrition and other medical conditions that lead to poor nutritional status among these women, which manifests as anemia. (8)

Diet plays a crucial role in averting the risk of anemia; however, many women with resource constraints do not have access to a quality diet. Due to several accessibility issues, most women consume a monotonous diet, which may be the major risk for developing anemia. (9) Further, knowledge about types of foods that are rich of iron is also very crucial. Data from Pakistan suggests that only $24.8 \%$ of women have knowledge about iron-rich food items. (5) These issues are even worse in coastal slums, where the most accessible food item is seafood and a vast majority of the households do not have access to other sources of food due to poverty and food insecurity. The use of gutka is also popular in these slums, and trends demonstrate that women are frequent consumers. (10)

In the context of coastal slums where health infrastructure is poor, formal education is not very common, and health indicators are dismal. (11-15) Thus, it is important to understand perceptions and experiences of women of reproductive age with access to iron-rich food and the intake of gutka among MWRA. Therefore, we conducted an exploratory study to understand knowledge, perception and experience of MWRA towards the use of iron-rich food item as a part of daily diet. We also have explored the behaviors of MWRA towards gutka intake. Additionally, we also performed a market survey to understand the pattern of availability of iron-rich food items at the community level.

\section{Methods}

\section{Study design and study setting}

This is an exploratory study. The study is phase two of a main study in which we conducted an analytical cross-sectional survey that aimed to determine the prevalence and predictors of anemia among a total sample of 557 nonpregnant MWRA (unpublished). To understand the perception and experiences, we conducted focus group discussions (FGDs) and in-depth interviews (IDIs). Furthermore, we also conducted a market survey using observational visits at different shops to assess the availability of different iron-rich food items in the community.

Study was conducted in Rehri Goth, one of the oldest coastal slums located in Bin Qasim Town, Karachi with a total population of approximately 42,000 people. (27) Data from the nongovernmental organization VITAL Pakistan Trust suggests that this area has high maternal and neonatal mortality at 300 per 100,000 live births and 57 per 1000 live births, respectively. (unpublished data) The community is deprived of basic hygiene and sanitation as well as key health services, such as basic skilled delivery facilities and routine immunization. (30)

\section{Theoretical framework}


The household-level and community-level environment provided the theoretical framework of anemia among nonpregnant MWRA. Figure 1 presents our understanding regarding how these characteristics may play an integral role in defining certain practices, such as the lack of inclusion of iron-rich food items

in daily dietary routine. $(8,10,16,17)$ Better understanding of these characteristics and the experiences of these women formed the basis of this exploratory study.

\section{Study population and sample size}

We approached nonpregnant MWRA who participated in phase one of the main study. Using purposive sampling, we approached MWRA from the same cohort of 557 women to participate in phase-two FGDs. We assured the representation of different age groups, ethnicity, and anemia categories. Additionally, we also approached community health workers for FGDs to explore their knowledge on the topic. Further, IDIs with different shopkeepers were also conducted to understand the key issues of availability of iron-rich food items. In this study, we reached the point of saturation after the fourth FGD (3 with community women and 1 with community health workers), and saturation was reached at the fourth IDI. The sample $(n=37)$ consisted of 24 women from the community (FGDs), 9 community health worker (FGD) and 4 shopkeepers (IDIs). Table 1 is presents more detailed information.

\section{Qualitative tools}

A topic guide was prepared using open ended questions composed of different probes to conduct FGDs and IDIs to explore and understand the phenomenon. In addition, practices regarding type of daily food consumption were explored to construct a potential theme on low-iron food consumption among participants. A checklist was designed and used to perform a market survey to observe the availability of a type of iron-rich food item at meat shops and grocery stores.

\section{Informed consent procedure}

For eligible participants, written informed consent was obtained by the research team in a local language (mostly Urdu and, where required, in the languages Sindhi and Pashto). The team members explained the details of the process of FGDs and IDIs accordingly. If a participant was eligible and agreed to undergo the procedure as explained, the research team would give the consent form to the participant or decision maker. If the participant could not read, a team member read it word-by-word to them in Urdu or the local language. The participants were allowed to ask any questions related to the consent form and trial procedure. If the participant/decision maker required additional time to make more informed decisions, the team allowed this opportunity and waited until a final voluntary decision was made. If the participant voluntarily agreed to participate, they signed the consent form in the presence of a witness. Specifically, either the form was duly signed or a thumb impression was provided by participant and the witness. The ethics committee approved the use of a thumb impression by the participant and witness if they could not read or write. A copy of informed consent was provided to all participants and attached in the file with the study ID. 


\section{Data collection}

FGDs and IDIs were undertaken by the investigator in a private, quiet room at the field office of VITAL Pakistan Trust. The initial topic guide was prepared from the literature and the experience of the investigators. Flexibility in the FGD and IDI structure allowed participants to discuss issues of interest to them. The topic guide was phrased more to allow discussion. Thus, participants followed their own string of beliefs. The topic guide was refined and expanded as the FGDs and IDIs progressed. These sessions were tape recorded, transcribed, translated and transferred to the sheet for data analysis. Each FGD and IDIs lasted for 50-60 minutes. Table 1 presents information on participant demographics and other details of FGDs and IDIs.

Further, the market survey was conducted using observational visits at different meat shops, grocery stores and vegetables/fruits carts. Rehri goth has 14 different neighborhoods/paras that are populated by different sociocultural and ethnic groups. We visited areas and identified different shops that were potential targets for our observational visits to map availability of different types of iron-rich food items. To identify shops, we initially obtained help from the health workers and community elders and approached these shops. After permission, each shop was visited 4 times on a weekly basis in a onemonth period to capture significant data on pattern of availability of iron-rich food items, such as meat, poultry, fruits, and vegetables.

\section{Data analysis}

We performed manual thematic analysis. Data obtained from the audio tapes were transcribed into scripts verbatim in word document. All quotes were encoded using the excel sheet. Using an inductive thematic approach, (18) data (quotes) were examined for recurrent instances of some type that were then systematically identified across the data set and grouped together by means of a coding system. Similar codes were grouped together into more general concepts, i.e., subcategories, and further categorized into main categories. To ensure reliability of data interpretations, analyses were performed independently by two investigators. Disagreements were discussed with the senior investigator until consensus was reached.

\section{Results}

The findings from the analysis helped in reforming a framework to explain key levels, which translated into poor accessibility of iron-rich food at the community level. Figure 2 represents the framework of understanding based on the findings and reframing of our conceptual framework, including household and community environment where these women are residing, enabling us to construct the specific behaviors that promote the use of iron-rich food items. The most appropriate quotes were chosen to illustrate each subcategory.

\section{Household environment}


Individual understanding of an issue

\section{Poor knowledge and understanding}

Most of the women in the community were not aware of which food items were rich in iron content. When women were asked to name some of these items, few said green vegetables, and a small number of women thought fruits were a rich source of iron.

"We don't know what the sources of iron (folaad) are in our food. I feel that it might be meat." (35-year-old female from Amin Jatt para)

Women belonging to the fishermen community believed that seafood is rich in iron as demonstrated by this comment:

"Fish and prawn are the main food items we use. It contains all we need. It is good enough."

(26-year-old female from Qasmani para)

There is lack of knowledge sharing between health workers and community women. Many community women mentioned that their interactions with health workers are not very informative and effective given that the healthcare workers themselves are poorly informed about healthy food.

"We don't know what they are trying to say, whatever they say is difficult to understand and most of the time they are in hurry. We don't understand what they say to us. They just come and talk and fill the forms." (45-year-old female from Dabla para)

\section{Self-preference in consuming a diet that lacks iron content}

In this community, meat is consumed at a reduced frequency. Meat is not sold regularly in the markets and is very expensive. Most of the families cannot purchase meat on a regular basis. People generally prefer fish and prawns because these items are easily available in the fishing community. Few participants mentioned having religious restrictions regarding eating meat:

"In my village, I don't see anyone selling meat, which you are talking about. It's all fish we like. We don't such as the taste of meat; it has some smell, which we don't like. I guess therefore no meat shop is here." (36-year-old female from Wiryani Para)

A health worker shared the following:

"Our community consumes a limited variety of food in meals. If you visit their home, either you see fish or potato curry. You will also find houses where nothing is made because they don't have money. Shops are also limited in this area. If my father has to buy good vegetables, fruits or meat, he has to go to main city, nothing here is good." (22-year-old health worker) 


\section{Family influence}

\section{Decision maker's decision on choice of food items}

In patriarchal societies, such as Pakistan, the male members are the main decision makers at the household level. However, in our findings regarding who decides the day to day menu, we found that there is shared decision making where the women, their husbands and other family members have an equal opportunity to decide. One woman provided the following comment:

"What to cook today, we decide mutually, there is no problem with that. Sometimes, my husband says, cook this, and sometime my mother-in-law. If I have to cook something, no one has a problem." (38-yearold female from Lalabad)

In a fishing community, the men are mostly out at sea, and women are the main decision makers for selecting food items with the limited available resources available to them.

"My husband and other male members at home are fishermen; they are at sea most of the time, so we cook whatever is available to us." (27-year-old female from Moosani para)

Further, gender preference in serving the meal first to the male members is common in the community and perceived as a common custom.

"I always serve my husband first, the best of curry and fresh Roti, this is my duty and I follow that. I eat at the end." (28-year-old female from Lalabad)

\section{Poor consumption of any type of meat in diet}

Consumption of meat from cattle is rare in this community, especially in the families of fishermen. The possible explanation may be embedded in the non-availability of meat shops and the lack of awareness of eating a variety of food that is essential to meet the nutritional requirement. It seems that eating seafood on daily basis or on a frequent basis has become a norm and a part of their behavior. The other factor associated with limited food choice is extreme poverty, which may affect the use of meat in the diet. One of the participants mentioned the following:

"We are poor fishermen. We cannot afford meat and things such as that to eat. We can only eat what we get free, the fish and prawn. This is only available free food for my home."(31-year-old female from Qasmani para)

Further, there are women who highlighted that potato consumption is very high at the household level. A woman mentioned the following:

"The most frequent food item is potato at our house, it is cheap and readily available and everyone loves it." (22-year-old female from Qasmani Para) 
$\underline{\text { Influence on use of gutka }}$

Family members who eat gutka are the major influencers in adopting this habit among women, especially after marriage.

"When I got married, I found that all my in-laws are eating it. Then, I also started it. I only took it once, I such as the taste and started using it now." (22-year-old female from Qasmani Para)

The following information was provided by a woman:

"We shared gutka with each other. Around my home, everyone chews gutka. I don't remember how I started it." (46-year-old female from Milkaye Para)

The women from the fishing community mentioned that gutka consumption is increasing daily, and people are prioritizing eat it instead of healthy food. One of the participants shared the following experience:

"This thing has become an addiction currently, we can survive without meat and fruits and other things you mentioned, what you call? Yeah, iron-rich diet; we can't survive without gutka." (39-year-old female from Dable para)

Many women mentioned that gutka is addicting, which compels them to eat now on a regular basis. Most of the women who were of a low socioeconomic background preferred to buy gutka due to their addiction to it. One of the females who was eating gutka said the following:

"I such as to eat it all the time, I such as it! The gutka makes me feel better, it's just 10-20Rs and cost of food is high, I such as to buy it."

Another woman highlighted the following:

"After eating gutka, I don't feel such as I am hungry, maybe this is the reason I am very weak. We are so poor, at least this help us." (31-year-old female from Dabla para)

\section{Household accessibility to iron-rich food items}

\section{Poor affordability}

Most of the participants revealed that cost of meat and fruits is substantially high, which possibly explains the poor consumption of these food items. The cost is linked to the willingness to purchase meat and other iron rich food. A female community member mentioned the following:

"You are asking if we can eat meat, see, imagine the cost of meat is I think 400-500 rupees per kg or maybe more. I cannot afford this. Even if I want to eat these things, I cannot buy them. My husband is poor." (39 year-old-female from Chasma Goth) 
Another woman mentioned the following:

"Here, we have no meat shop. First, the cost of meat, and then in order to purchase it someone has to go to the main city after arranging transportation. This is too much." (40-year-old female from Khalifa Jatt)

\section{Community environment}

\section{Physical environment}

\section{Appeal of iron-rich food items}

There are very few meat shops in the community bazars. Although meat is available in the geographical area where Pashtun and Baloch communities are located, but the fishing community has no meat shops with the exception of poultry shops, which are also very limited. A community midwife mentioned this limitation in the following statement:

"In our community, there is no meat shop. People don't such as to eat meat; no one wants to open the shop where people are not willing to buy meat. At Eid (Eid-ul-Adha, a religious festival), people sacrifice cattle; this is the only time when we eat meat. Even, many don't such as the taste though." (24-year-old midwife from Shaikh para)

Furthermore, a community woman provided the following information:

"We don't such as to eat meat, so no shop is here. What will that person do if no one will buy? Additionally, meat is expensive, it's just not we don't want to eat. This is also a reason." (45-year-old female from Moosani para)

\section{Availability of iron-rich food items}

\section{Food prices}

Many of the shopkeepers link the poor consumption of different food items with cost and highlighted that community has limited purchasing power to buy expensive food items, such as meat and fruits, which ultimately affect the consumption of a variety of foods.

"See, meat is 800-900 Rupees per kg, and mutton is even more expensive. What do you think, can these people afford it? No! They cannot. Look at the cost of Mangoes, 120 to 200 Rupees per kg. No can buy these expensive items if they have many members at home." (A fruit cart owner at Jabal))

"Poor people cannot even afford to buy wheat and rice; they are struggling to buy them. No one came to me for monthly ration, rather day to day small quantity only." (Grocery shopkeeper in Moosani para)

Poor availability. 
Meat shops are scarce in the fishing community. If someone must buy meat, the only option is the main city, as mentioned by one of the shopkeepers:

"There is no meat shop in this whole village. No one wants to sell it because the market is not good here. See, I have only a few chickens available; very rarely someone comes to buy it also. Meat has no market." (Poultry shop in Moosani para)

\section{Social environment}

\section{Peer pressure to consume a monotonous diet}

Woman from the fishing community are mostly reliant on a monotonous diet. This behavior is adopted from other community members and relatives who have been practicing it for past years. A similar experience was reiterated by one of the community health workers, who has been working on improving maternal and child health in the area for last 5 years.

"It is very difficult to communicate to our people to eat healthy diet. They can only eat meat in the form of fish and prawns, which are free to them if their husband is a fisherman. They cannot afford beef or mutton; this is very expensive for them. Few only eat once in a year - at the occasion of Eid-ul-Adha." (21year-old community health worker from Sache Dino)

\section{Findings from market survey}

The availability of meat shops is very scarce. For a population of approximately 42,000 people, only 3 shops were available, and the availability of meat was only $41.7 \%$ at the time of the observation visits, and mutton and lamb meat was not available at all. Specifically, regarding poultry meat, 9 shops where identified, and $63.9 \%$ of the time poultry meat was available at the shops during observation visits. We also found 8 different fruits carts in the community. Most of them are static in location, and only two were relocated on a daily basis. The availability of fruits was very erratic and subject to season. The most frequently available fruit was watermelon (84.4\%), and the remainder of the fruits, which are rich source of iron, exhibited varied availability from $0 \%$ for prunes to $65.6 \%$ for apples. Specifically, regarding vegetable carts, which are mostly mobile, only spinach was found to be available on $63.6 \%$ of the time during observation visits, whereas other iron-rich vegetables were marginally available. Grocery shops are readily available in the community. Chickpea and lentils are available $82.7 \%$ and $90.4 \%$ of the time, respectively. Eggs were available $92.3 \%$ of the time. However, the shopkeeper mentioned that they did not replenish the stock for at least one month with the exception of eggs. Further, the availability of red beans was very limited (3.8\%) as these beans were only available at one shop during two observations. We also observed that gutka shops are readily available in the community.

\section{Discussion}

Diet plays a pivotal role in defining the anemia status among MWRA. However, access to an iron-rich diet, which helps MWRA to improve their health status with regard to anemia, is limited in Rehri Goth. MWRA 
are facing many problems in accessing an iron-rich diet. The knowledge and awareness MWRA have about the types of foods that are important sources of iron and the benefits of including these iron-rich food items in a regular diet are lacking. Knowledge provided by health workers visiting the households is critical, (19) but this is also suboptimal in many contexts, highlighting the need for more training and robust tools to spread this information. Family decision making is also an essential driver to improve maternal health. (20) In many such communities, women have no power to make decisions regarding their own health. Elders and husbands are the key decision makers, and this results in barriers in accessing food that women require to maintain a healthy status. In this study, similar findings are highlighted.

Further, the woman is typically the last person to eat and often has to eat the leftovers. In many communities, such as the study setting, women typically eat at the end when everyone else has had their fill and are thus left with a reduced amount of food. (21) The situation is worse in households where poverty is prevalent, and food insecurity exists due to poor household income. In coastal slums, where many people live below the poverty line, people cannot buy variety of food and primarily rely on seafood as one of the primary sources of food consumption. (17) Due to this poor purchasing power, the availability of meat shops is also very scarce, an important finding of our study. In Rehri Goth, many women are consuming a diet that is not rich in iron, and accessibility (both physical accessibility and affordability) to red meat is decreasing, hence raising a huge concern in this community. In the fishing community, where the most frequently consumed meat source is seafood, the MWRA have reported cultural barriers in achieving a balance between red meat consumption and seafood. Seafood is readily available and generally free-of-cost in the fishing community compared to other meat sources, which are costly and many cannot afford. Poverty and food insecurity in Rehri Goth play an important role in the availability of food and lead to a limited and monotonous food intake, resulting in nutritional deficiency and anemia. This phenomenon may have stemmed from a lack of understanding of the value of varied dietary intake and the importance of an iron-rich diet.

"See! Fish and prawn are what we capture from the sea. It is readily available, and no money is required to purchase it. Because, we have it on our own. We can even catch small fish from not too far in the sea. The meat, we cannot afford it and we don't eat it here (at in-laws), when I was unmarried and living in Liyari, my father used to bring it once in month. Since the last 15 years, I never eat it here. They just don't such as it and can't afford it. Even you will not find any meat shop here for the people here." (37-yearfemale from Milkaye para)

Poor dietary intake, which is associated with both quantity and quality in term of micronutrients such as, such as iron-rich foods, is the major factor associated with anemia. (8) The most affected population is resource-poor subsistence fisherman as their, household income is based on seasonal fishing, which is a common activity in the coastal belt of Karachi. Thus, people may have developed certain behaviors that serve as barriers in accessing quality food and lead to poor dietary practices. A poor monotonous diet, which may be linked with sociocultural behaviors, is likely to cause multiple micronutrient deficiencies, and this phenomenon is explored through our finding as well. (9) 
"I truly don't such as its taste (the beef or mutton). When I was pregnant, the doctor told me to eat liver as much as I can, but I never did. How can I eat something which I don't like? I only such as fish, the fish which we eat regularly." (37 year-old-female from Qasmani para)

Substance abuse in the form of chewed or smokeless tobacco may be associated with anemia among MWRA in developing countries, such as Pakistan. (22) Gutka is the most common form of smokeless tobacco that is made of tobacco with areca nut, catechu, slake lime and other ingredients. The findings from this study have revealed that of nonpregnant MWRA who consumed gutka (i.e., $38 \%$ consumers of gutka among the study participants) on a regular basis, many were anemic (results from phase- 1 of this study). Although this study has not established any causal relation between gutka and anemia among these MWRA, a possible explanation for the high prevalence of anemia among gutka consumers may be linked with the type of ingredients present, which may hinder the absorption of iron from the intestines. In addition, there is also ambiguity in the type of ingredients used in the gutka formulation, which may be different at different geographical location within countries. The use of gutka has penetrated the community through peer pressure, where community influencers play a crucial role in the high use and prevalence in community as noted in this study. In areas with extreme poverty and hunger, gutka is used to avoid hunger. This prominent theme is supported by qualitative findings. Many gutka users have shared the experience that gutka is addictive and they cannot avoid using it. Many family members are chronic gutka users.

"Whenever I have it (gutka), I feel relaxed and calm, no stress of being hungry when we have no food. We eat gutka and get sleep well." (41-year-old female from Sachedina para)

\section{Limitations}

This study only explored the views of MWRA and shopkeepers. Male community members and other decision maker's views were not explored. In addition, responses and experiences shared during IDIs or FGDs were self-reported and therefore there may be information bias. However, we are still able to highlight a very important aspect of maternal health in coastal slums related to anemia.

\section{Abbreviations}

\begin{tabular}{ll} 
MWRA & Married women of reproductive age \\
\hline FGDs & Focus group discussions \\
\hline IDIs & In-depth interviews
\end{tabular}

\section{Declarations}

\section{Competing interests}

The authors declare that they have no competing interests. 


\section{Funding}

This study is not funded by any granting agency or sponsor.

\section{Ethics and consent to participate}

Ethical approval was obtained from the Ethical Review Committee (5090-CHS-ERC-17) of AKU. Written informed consent was administered in a local language to eligible participants and explained the research. In cases where MWRA were not educated, consent was documented by a thumbprint in the presence of a literate witness.

\section{Availability of the data and material}

The deidentified dataset is available from the corresponding author upon reasonable request.

\section{Consent publication}

Not applicable

\section{Authors' contribution}

AM: conceived the idea and study and developed the protocol, tools, and standard operating procedures. AM and YS performed the analysis. YS and SS: contributed to the design of the study and developed the study protocol and standard operating procedures. AM, DAC, and ET: drafted the manuscript. AM: implemented and supervised the study. AM and UK: conducted the FGDs and IDIs, coordinated the activities and contributed to the manuscript. All authors provided feedback and approved the final manuscript.

\section{Acknowledgments}

The authors would like to thank the participants for their involvement, the research team for their contributions.

\section{References}

1. World Health Organization. Global prevalence of vitamin A deficiency in populations at risk 19952005: WHO global database on vitamin A deficiency.

2. Stevens GA, Finucane MM, De-Regil LM, Paciorek CJ, Flaxman SR, Branca F, Peña-Rosas JP, Bhutta ZA, Ezzati M, Nutrition Impact Model Study Group. Global, regional, and national trends in haemoglobin concentration and prevalence of total and severe anaemia in children and pregnant and non pregnant women for 1995-2011: a systematic analysis of population-representative data. The Lancet Global Health. 2013 Jul 1;1(1):e16-25. 
3. World Health Organization. Trends in maternal mortality 2000 to 2017: estimates by WHO, UNICEF, UNFPA, World Bank Group and the United Nations Population Division.

4. Rahman MM, Abe SK, Rahman MS, Kanda M, Narita S, Bilano V, Ota E, Gilmour S, Shibuya K. Maternal anemia and risk of adverse birth and health outcomes in low-and middle-income countries: systematic review and meta-analysis, 2. The American journal of clinical nutrition. 2016 Feb 1;103(2):495-504.

5. Bhutta Z, Soofi S, Zaidi S, Habib M, Hussain I. National nutrition survey Pakistan. Pakistan): Aga Khan University, Pakistan Medical Research Council, Nutrition Wing Cabinet Division of Goverment of Pakistan, UNICEF. 2011.

6. World Health Organization. Haemoglobin concentrations for the diagnosis of anaemia and assessment of severity. World Health Organization; 2011.

7. Kozuki N, Lee AC, Katz J. Moderate to severe, but not mild, maternal anemia is associated with increased risk of small-for-gestational-age outcomes. The Journal of nutrition. 2012;142(2):358-62.

8. Ghose B, Tang S, Yaya S, Feng Z. Association between food insecurity and anemia among women of reproductive age. PeerJ. 2016;4:e1945.

9. Yeneabat T, Adugna H, Asmamaw T, Wubetu M, Admas M, Hailu G, Bedaso A, Amare T. Maternal dietary diversity and micronutrient adequacy during pregnancy and related factors in East Gojjam Zone, Northwest Ethiopia, 2016. BMC pregnancy and childbirth. 2019 Dec;19(1):1-9.

10. Jose S, Antony SC, Isaac BR. Impact of Knowledge, Attitude and Practice on Anemia status among women in coastal Kochi, Kerala. Int. J of Multidisciplinary and Current Research. 2016 Mar;4:295-8.

11. Un-Habitat. State of the World's Cities 2008-2009: Harmonious Cities: Earthscan; 2008.

12. Save the Children. The Urban Disadvantage. State of the world's mothers 2015. 2015.

13. Sassen S. Cities in a world economy: Sage Publications; 2011.

14. Eckert S, Kohler S. Urbanization and health in developing countries: a systematic review. World Health Popul. 2014;15(1):7-20.

15. Fernandez A, Mondkar J, Mathai S. Urban slum-specific issues in neonatal survival. Indian Pediatrics. 2003;40(12):1161-6.

16. Akter T. Migration and living Conditions in urban slums: implications for food security. Unnayan Onneshan, The Innovators, Centre for Research and Action on Development, Dhaka, Bangladesh. 2009.

17. Salagrama V. Trends in poverty and livelihoods in coastal fishing communities of Orissa State, India: Food \& Agriculture Org.; 2006.

18. Silverman D: Qualitative Research: Theory, Method and Practice. 2004, London, Thousand Oaks, New Delhi: Sage Publications, Second

19. Rizvi F. Impact of maternal education, and socioeconomic status on maternal nutritional knowledge and practices regarding iron rich foods and iron supplements. Ann Pak Inst Med Sci. 2012;8(2):1015 . 
20. Danforth EJ, Kruk ME, Rockers PC, Mbaruku G, Galea S. Household decision-making about delivery in health facilities: evidence from Tanzania. Journal of health, population, and nutrition. 2009 Oct;27(5):696.

21. Ramachandran N. Women and food security in South Asia: Current issues and emerging concerns. InFood insecurity, vulnerability and human rights failure 2007 (pp. 219-240). Palgrave Macmillan, London.

22. Subramoney S, Gupta PC. Anemia in pregnant women who use smokeless tobacco. Nicotine \& tobacco research. 2008;10(5):917-20.

\section{Tables}

Table 1 | Demographic characteristics of focus group participants $(n=37)$ 


\begin{tabular}{|c|c|c|}
\hline & Focus Group Discussions a & In-depth interviews ${ }^{\text {b }}$ \\
\hline Gender & $\mathbf{N}$ & $\mathbf{N}$ \\
\hline Female & 33 & - \\
\hline Male & - & 4 \\
\hline \multicolumn{3}{|l|}{ Age Group } \\
\hline $18-24$ years & 12 & 1 \\
\hline $25-34$ years & 11 & 2 \\
\hline $35-44$ years & 9 & 1 \\
\hline $45-49$ years & 1 & - \\
\hline \multicolumn{3}{|l|}{ Ethnicity } \\
\hline Sindhi & 13 & 2 \\
\hline Pashtun & 6 & 1 \\
\hline Balochi & 5 & 1 \\
\hline Urdu & 3 & - \\
\hline Bengali & 3 & - \\
\hline Punjabi & 3 & - \\
\hline \multicolumn{3}{|l|}{ Education } \\
\hline No formal education & 19 & 2 \\
\hline Primary & 5 & - \\
\hline Middle & 5 & 1 \\
\hline Secondary & 3 & 1 \\
\hline Bachelors or above & 1 & - \\
\hline \multicolumn{3}{|c|}{$\begin{array}{l}\text { a } A \text { total of three FGDs were conducted with nonpregnant MWRA with a total participant count of } 24 \\
\text { Further, one FGD was conducted with community health workers with total participant count of } 9 .\end{array}$} \\
\hline
\end{tabular}

\section{Table 2 | Findings of market survey}




\begin{tabular}{|c|c|c|c|c|}
\hline Food item & $\begin{array}{l}\text { Geographical } \\
\text { visited for } \\
\text { observation }\end{array}$ & $\begin{array}{l}\text { Availability of } \\
\text { specific shop in } \\
\text { the area }\end{array}$ & $\begin{array}{l}\text { Observations at } \\
\text { each available } \\
\text { shop a }\end{array}$ & $\begin{array}{l}\text { Availability of } \\
\text { specific iron-rich } \\
\text { food item }\end{array}$ \\
\hline & $\mathbf{N}$ & $N(\%)$ & $\mathbf{N}$ & $\mathrm{N}(\%)$ \\
\hline \multicolumn{5}{|l|}{ Meat shops } \\
\hline Beef & \multirow[t]{4}{*}{14} & \multirow[t]{4}{*}{$3(21.4)$} & 12 & $5(41.7)$ \\
\hline Mutton & & & 12 & $0(0.0)$ \\
\hline Lamb & & & 12 & $0(0.0)$ \\
\hline Liver & & & 12 & $1(8.3)$ \\
\hline \multicolumn{5}{|l|}{ Poultry shops } \\
\hline $\begin{array}{l}\text { Chicken } \\
\text { meat }\end{array}$ & \multirow[t]{2}{*}{14} & \multirow[t]{2}{*}{$9(64.3)$} & 36 & $23(63.9)$ \\
\hline Liver & & & 36 & $23(63.9)$ \\
\hline \multicolumn{5}{|c|}{ Fruits shops/carts } \\
\hline Dates & \multirow[t]{8}{*}{14} & \multirow[t]{8}{*}{$8(57.1)$} & 32 & $13(40.6)$ \\
\hline Apricot & & & 32 & $12(37.5)$ \\
\hline Prunes & & & 32 & $0(0.0)$ \\
\hline Apple & & & 32 & $21(65.6)$ \\
\hline Watermelon & & & 32 & $27(84.4)$ \\
\hline Strawberries & & & 32 & $8(25.0)$ \\
\hline Figs & & & 32 & $11(34.4)$ \\
\hline Pomegranate & & & 32 & $7(21.9)$ \\
\hline \multicolumn{5}{|c|}{ Major green vegetable shops/cart } \\
\hline Spinach & \multirow[t]{6}{*}{14} & \multirow[t]{6}{*}{$11(78.6)$} & 44 & $28(63.6)$ \\
\hline Mustard leaf & & & 44 & $8(18.2)$ \\
\hline Bitter gourd & & & 44 & 8 (18.2) \\
\hline $\begin{array}{l}\text { Indian } \\
\text { squash }\end{array}$ & & & 44 & $3(6.8)$ \\
\hline Capsicum & & & 44 & $3(6.8)$ \\
\hline Qasoori & & & 44 & $1(2.3)$ \\
\hline
\end{tabular}


methi

Moongray

Green pea

Beetroot

Grocery shop

Red beans $\quad 14$

Chickpeas

Lentil

Eggs

\section{Pan shop}

Gutka 14
44

44

44

$13(92.9)$

52

52

52

52

56
$4(9.1)$

$0(0.0)$

$3(6.8)$

$2(3.8)$

43 (82.7)

47 (90.4)

$48(92.3)$

a Each shop was visited four times on a weekly basis during the one-month period to capture in-depth data on patterns.

\section{Figures}

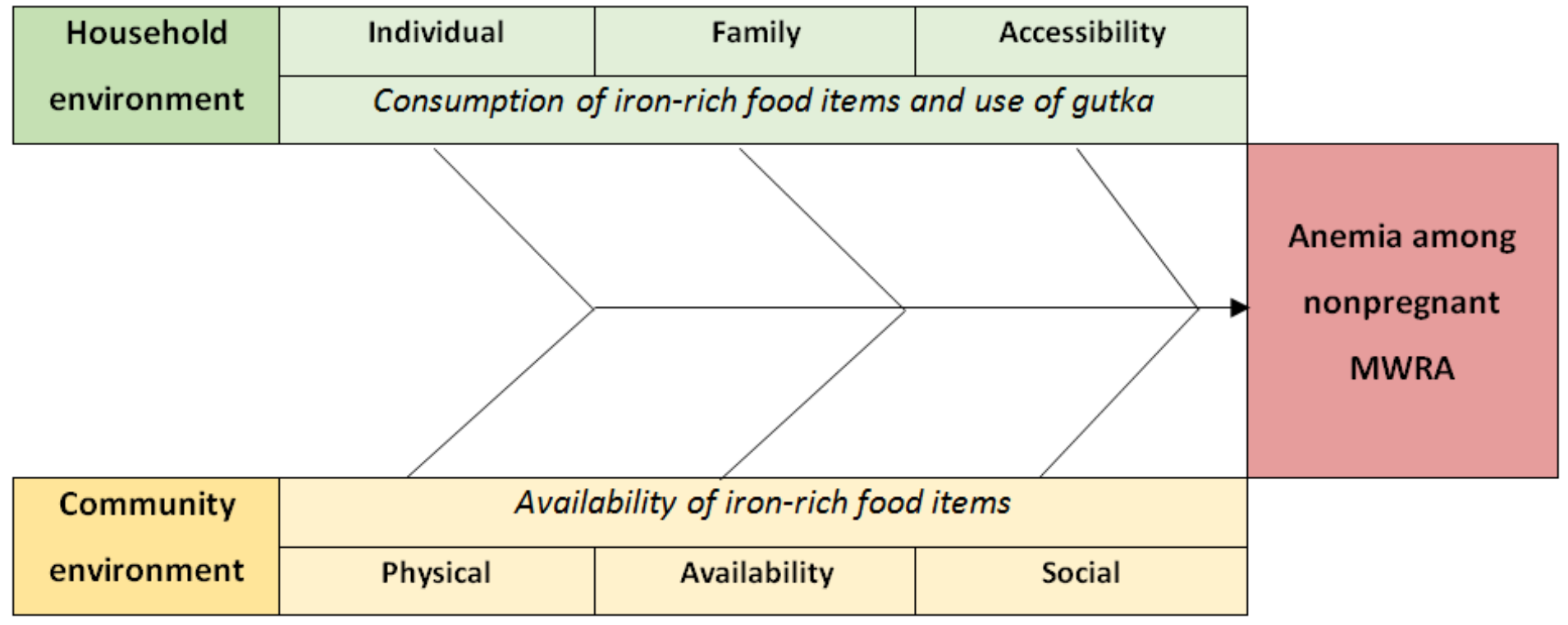

\section{Figure 1}

Theoretical framework 


\begin{tabular}{|c|c|c|c|c|}
\hline \multirow[b]{3}{*}{$\begin{array}{l}\text { Household } \\
\text { environment }\end{array}$} & \multicolumn{3}{|c|}{ Low consumption of iron-rich food items } & \\
\hline & Individual & Family & Accessibility & \\
\hline & $\begin{array}{l}\text { Poor knowledge and } \\
\text { understanding } \\
\text { Self-preference in } \\
\text { consuming a diet which } \\
\text { lacks iron content }\end{array}$ & $\begin{array}{l}\text { Decision maker's decision } \\
\text { on choice of food items } \\
\text { Poor consumption of any } \\
\text { type of meat in diet } \\
\text { Influence of the use of } \\
\text { gutka }\end{array}$ & Poor affordability & \\
\hline & & & & $\begin{array}{c}\text { Anemia among } \\
\text { nonpregnant } \\
\text { MWRA }\end{array}$ \\
\hline
\end{tabular}

\begin{tabular}{|c|l|l|l|}
\hline \multirow{2}{*}{$\begin{array}{c}\text { Community } \\
\text { environment }\end{array}$} & $\begin{array}{l}\text { Appeal of iron-rich food } \\
\text { items }\end{array}$ & $\begin{array}{l}\text { Food prices } \\
\text { Poor availability }\end{array}$ & $\begin{array}{l}\text { Peer pressure to consume } \\
\text { a monotonous diet } \\
\text { Peer pressure to use } \\
\text { gutka }\end{array}$ \\
\cline { 2 - 4 } & \multicolumn{2}{|c|}{ Physical } & \multicolumn{2}{|c|}{ Availability } & Social \\
\cline { 2 - 4 } & \multicolumn{2}{|c|}{ Low accessibility to iron-rich food items } \\
\hline
\end{tabular}

\section{Figure 2}

Updated framework after thematic analysis

\section{Supplementary Files}

This is a list of supplementary files associated with this preprint. Click to download.

- STROBEchecklistcrosssectionalOct52020.doc

- MarketsurveyplusIDIsguides.pdf

- FGDguide.pdf 